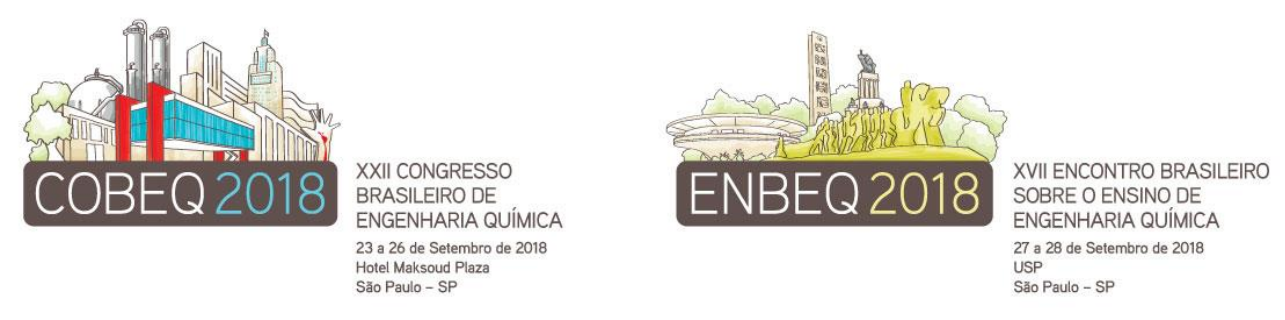

\title{
CLARIFICAÇÃO DE ÁGUAS DO PROCESSO SIDERÚRGICO DE LAMINAÇÃO USANDO TANINO COMO AUXILIAR DE COAGULAÇÃ̃O
}

\author{
GONÇALVES PM ${ }^{1}$, MONTEIRO MB ${ }^{1}$, SANTOS APNM $^{1}$, PIAZZI ACF ${ }^{1}$ e BATISTA MS ${ }^{2}$ \\ ${ }^{1}$ Universidade Federal de São João Del Rei, Graduação em Engenharia Química \\ ${ }^{2}$ Universidade Federal de São João Del Rei, Departamento de Engenharia Química \\ E-mail: marcelobatista@ufsj.edu.br
}

\begin{abstract}
RESUMO - Esse trabalho tem como objetivo avaliar o uso do tanino como coagulante auxiliar, no intuito de reduzir a concentração de cloreto férrico que é empregada nas estações de tratamento. $O$ efluente utilizado é proveniente do processo de laminação e a dosagem ideal de cloreto férrico foi determinada através de ensaios em jar test variando a sua dosagem de 1,0-80,0 mg/L. Para avaliar a redução de cloreto férrico, fixou-se a concentração de 30,0 $\mathrm{mg} / \mathrm{L}$ de tanino e variou-se a concentração de cloreto férrico na faixa de 1,0-20,0 $\mathrm{mg} / \mathrm{L}$. Os parâmetros analisados no efluente foram turbidez, cor, sólidos suspensos, $\mathrm{pH}$, teores de ferro, cloreto e fosfato. Os resultados mostraram que a dosagem ideal de cloreto férrico foi de 20,0 $\mathrm{mg} / \mathrm{L}$. Verificou-se que o uso combinado de 30,0 $\mathrm{mg} / \mathrm{L}$ de tanino reduziu 75,0\% do cloreto férrico, promovendo a redução de 88,8\% da turbidez, 26,9\% da cor, 88,4\% de sólidos suspensos totais, $94,4 \%$ de ferro e 77,8\% de fosfato. $O$ tanino é uma alternativa promissora para uso no processo de clarificação de água industrial, pois além de atuar na remoção de partículas finas, o lodo gerado é biodegradável.
\end{abstract}

\section{INTRODUÇÃO}

A reutilização da água industrial é uma alternativa que visa diminuir a captação de recursos hídricos e reduzir o impacto causado pela contaminação do corpo receptor, quando ocorre mau gerenciamento do efluente gerado em alguns processos. Dessa forma, uma planta industrial que possui um sistema de tratamento capaz de adequar o efluente para o reuso, contribui para que haja equilíbrio entre processo produtivo e o meio ambiente (SÁNCHEZ et al., 2010).

Os tratamentos físico-químicos que o efluente é submetido visam à clarificação do mesmo e o controle quantitativo de parâmetros como: pH, a turbidez, a cor, a concentração de sólidos suspensos totais, íons cloreto, ferro e fosfato. O descontrole desses parâmetros pode ocasionar contaminações na linha de produção, além de tornar os equipamentos e tubulações susceptíveis a incrustações e processos corrosivos, o que condiciona aumento dos custos operacionais associados à manutenção (HAMEED et al., 2016).

As rotas de clarificação do efluente que envolvem o uso de agentes coagulantes/floculantes são atrativas devido à alta eficiência na remoção de particulados. Entretanto, coagulantes baseados em compostos químicos não biodegradáveis, como os sais de ferro e alumínio, contribuem 


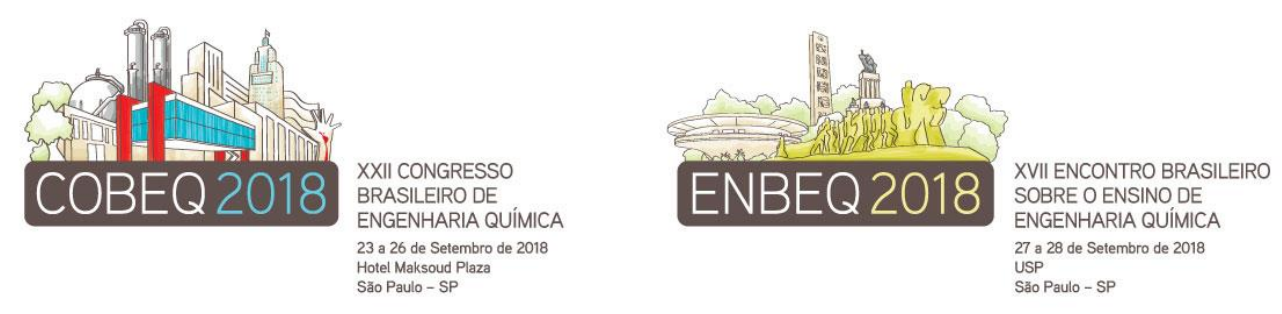

fortemente para a geração de lama com alto teor de substâncias que são nocivas à saúde humana e ao meio ambiente. Uma alternativa promissora é o emprego de coagulantes naturais, como os coagulantes a base de tanino, os quais geram lama biodegradável e menos tóxica (GUO et al., 2015). O custo total da operação com o tanino comercial pode vir a ser inferior ao custo com o cloreto férrico, uma vez que o tanino é efetivo em uma faixa ampla de $\mathrm{pH}$, sem consumir a alcalinidade do meio. Logo, seu uso exclusivo não exige etapas posteriores para correção do $\mathrm{pH}$ (ANTOV et al., 2012).

Neste cenário, esse trabalho visa à avaliação do desempenho do coagulante polieletrólito catiônico a base de tanino como auxiliar do cloreto férrico na clarificação do efluente proveniente do processo de laminação, de modo a reduzir a dosagem de cloreto férrico. Para que o efluente possa ser reutilizado no processo industrial de laminação, é necessário adequá-lo aos seguintes parâmetros: Turbidez $<10,00$ NTU, Ferro $<2,00$ mg/L, Sólidos Suspensos Totais $(\mathrm{SST})<10,00$ $\mathrm{mg} / \mathrm{L}$ e Fosfato $<1,00$.

\section{PROCEDIMENTO EXPERIMENTAL}

O efluente utilizado foi coletado na entrada da Estação de Tratamento de Efluentes (ETE) de laminação de uma siderúrgica em Minas Gerais. A Tabela 1 apresenta as caracterizações realizadas no efluente de acordo com o Standard Methods for the Examination of Water and Wastewater (ALPHA, 2012). A quantificação dos parâmetros (turbidez, cor, sólidos suspensos, $\mathrm{pH}$, teores de ferro, cloreto e fosfato) foi utilizada como base para definir as dosagens ideais dos coagulantes cloreto férrico e tanino.

Tabela 1 - Metodologias de caracterização do efluente de laminação.

\begin{tabular}{ccc}
\hline Parâmetros & Unidades & Métodos \\
\hline Turbidez & NTU & $2130-\mathrm{B}$ \\
Cor & u.c. & 2120 color $-\mathrm{B}$ \\
Sólidos Suspensos Totais (SST) & $\mathrm{mg} / \mathrm{L}$ & $2540-\mathrm{B}$ \\
Ferro & $\mathrm{mg} / \mathrm{L}$ & $3500 \mathrm{Fe}$ iron $-\mathrm{B}$ \\
Cloreto & $\mathrm{mg} / \mathrm{L}$ & $4500 \mathrm{Cl}^{-}-\mathrm{D}$ \\
pH & - & $4500 \mathrm{H}^{+}-\mathrm{B}$ \\
Fosfato & $\mathrm{mg} / \mathrm{L}$ & $4500-\mathrm{P} \mathrm{Phosphorus}-\mathrm{C}$ \\
\hline
\end{tabular}

A dosagem ideal de cloreto férrico foi determinada através de ensaios em jar test variando a sua dosagem de 1-80 mg/L. Para avaliar a redução de cloreto férrico, fixou-se a concentração de $30 \mathrm{mg} / \mathrm{L}$ de tanino e variou-se a concentração de cloreto férrico na faixa de 1-20 mg/L.

Os ensaios em jar test foram realizados com $1 \mathrm{~L}$ de efluente em cada jarro. Após as dosagens dos coagulantes, utilizou a velocidade de rotação de $150 \mathrm{rpm}$ durante $1 \mathrm{~min}$, seguido da velocidade de $40 \mathrm{rpm}$ durante $15 \mathrm{~min}$. Após a agitação, as misturas permaneceram em repouso por $15 \mathrm{~min}$. As alíquotas foram coletadas para medidas de turbidez, cor, sólidos suspensos, $\mathrm{pH}$, teores de ferro, cloreto e fosfato. 

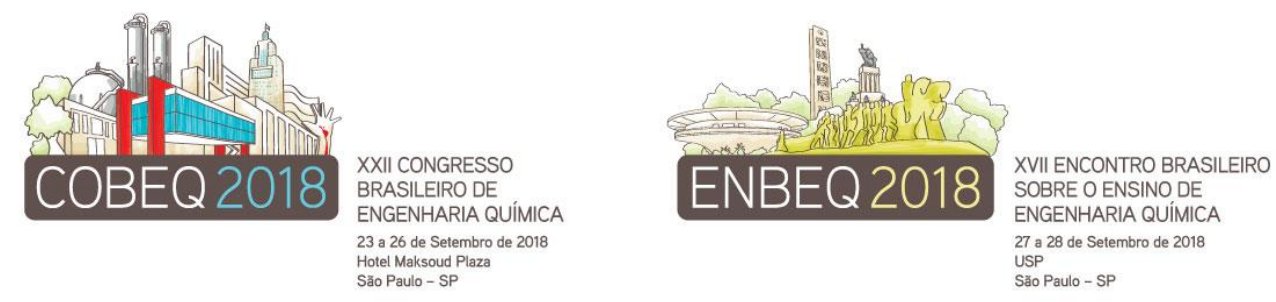

\section{RESULTADOS E DISCUSSÃO}

A Tabela 2 apresenta o resultado da caracterização do efluente de laminação coletado na entrada da ETE.

Tabela 2 - Caracterização do efluente bruto de laminação.

\begin{tabular}{cccccccc}
\hline Parâmetros & $\begin{array}{c}\text { Turbidez } \\
(\mathbf{N T U})\end{array}$ & $\begin{array}{c}\text { Cor } \\
(\text { u.c. })\end{array}$ & $\begin{array}{c}\text { SST } \\
(\mathbf{m g} / \mathbf{L})\end{array}$ & $\mathbf{p H}$ & $\begin{array}{c}\text { Ferro } \\
(\mathbf{m g} / \mathbf{L})\end{array}$ & $\begin{array}{c}\text { Cloreto } \\
(\mathbf{m g} / \mathbf{L})\end{array}$ & $\begin{array}{c}\text { Fosfato } \\
(\mathbf{m g} / \mathbf{L})\end{array}$ \\
\hline Amostra Bruta & 53,70 & 42,00 & 86,00 & 8,38 & 14,20 & 142,26 & 4,50 \\
\hline
\end{tabular}

A Tabela 3 apresenta os resultados de turbidez dos ensaios em jar test com variação da dosagem de cloreto férrico. Nota-se que a menor dosagem de cloreto férrico capaz de atingir turbidez menor que $10 \mathrm{NTU}$, considerada dosagem ideal, foi de $20,0 \mathrm{mg} / \mathrm{L}$.

Tabela 3 - Resultados de turbidez com a variação da dosagem de cloreto férrico.

\begin{tabular}{ccccccc}
\hline $\begin{array}{c}\text { Dosagem de cloreto } \\
\text { férrico (mg/L) }\end{array}$ & $\mathbf{1 , 0}$ & $\mathbf{5 , 0}$ & $\mathbf{1 0 , 0}$ & $\mathbf{2 0 , 0}$ & $\mathbf{4 0 , 0}$ & $\mathbf{8 0 , 0}$ \\
\hline Turbidez (NTU) & 29,30 & 31,40 & 15,10 & 6,47 & 3,72 & 1,11 \\
\hline
\end{tabular}

Conforme observado na Tabela 4 , a dosagem de $20,0 \mathrm{mg} / \mathrm{L}$ de cloreto férrico proporcionou a redução de $87,9 \%$ da turbidez, $38,6 \%$ de cor, $93,0 \%$ de SST, $88,7 \%$ do teor de ferro e $77,8 \%$ no teor de fosfato. Entretanto, observou-se um aumento de 6,7\% no teor de cloreto, em relação à amostra bruta.

Tabela 4 - Jar test com a combinação dos coagulantes.

\begin{tabular}{cccccccc}
\hline & $\begin{array}{c}\text { Turbidez } \\
\text { (NTU) }\end{array}$ & $\begin{array}{c}\text { Cor } \\
(\mathbf{u . c} .)\end{array}$ & $\begin{array}{c}\text { SST } \\
(\mathbf{m g} / \mathbf{L})\end{array}$ & $\mathbf{p H}$ & $\begin{array}{c}\text { Ferro } \\
\text { Total } \\
(\mathbf{m g} / \mathbf{L})\end{array}$ & $\begin{array}{c}\text { Aumento } \\
\text { de Cloreto } \\
(\%)\end{array}$ & $\begin{array}{c}\text { Fosfato } \\
(\mathbf{m g} / \mathbf{L})\end{array}$ \\
\hline Amostra Bruta & 53,70 & 42,00 & 86,00 & 8,38 & 14,20 & - & 4,50 \\
Cloreto Férrico 20,0 mg/L & 6,47 & 25,80 & 6,00 & 8,21 & 1,60 & 6,72 & $<1,00$ \\
$\quad \begin{array}{c}\text { Tanino 30,0 mg/L + } \\
\text { Cloreto Férrico 20,0 mg/L }\end{array}$ & 1,00 & 19,10 & 2,00 & 8,76 & 0,80 & 4,48 & $<1,00$ \\
$\quad \begin{array}{c}\text { Tanino 30,0 mg/L + } \\
\text { Cloreto Férrico 15,0 mg/L }\end{array}$ & 0,98 & 21,20 & 5,00 & 8,83 & 0,80 & 4,65 & $<1,00$ \\
$\quad \begin{array}{c}\text { Tanino 30,0 mg/L + } \\
\text { Cloreto Férrico 10,0 mg/L }\end{array}$ & 1,00 & 16,50 & 3,00 & 8,77 & 0,50 & 2,00 & $<1,00$ \\
$\quad \begin{array}{c}\text { Tanino 30,0 mg/L + } \\
\text { Cloreto Férrico 5,0 mg/L }\end{array}$ & 6,01 & 30,70 & 10,00 & 8,30 & 0,80 & 1,83 & $<1,00$ \\
$\quad \begin{array}{c}\text { Tanino 30,0 mg/L + } \\
\text { Cloreto Férrico 1,0 mg/L }\end{array}$ & 6,14 & 31,60 & 13,00 & 8,38 & 0,50 & 0,84 & 1,10 \\
\hline
\end{tabular}



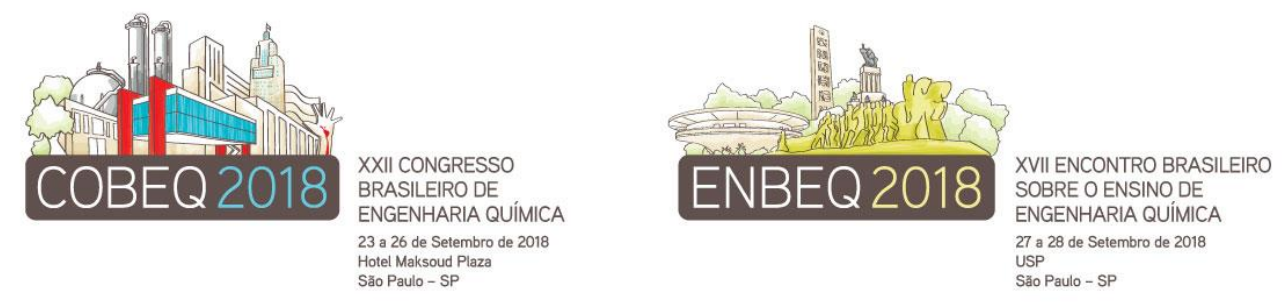

Os resultados da combinação dos coagulantes químico (cloreto férrico) e orgânico (tanino) mostraram que a redução da turbidez, cor, SST e do teor de ferro foi maior na presença do tanino (Tabela 4). Essa maior eficiência de remoção pode estar associado à capacidade do tanino em adsorver metais dissolvidos no efluente, permitindo a precipitação desse íon e, consequente, sua remoção do meio (THAKURM; CHOUBEY, 2014). Essa maior remoção pode estar associado às características químicas do tanino, tais como: estrutura da cadeia molecular, capacidade de desestabilizar partículas coloidais e remover finos do efluente.

Por meio da combinação dos coagulantes é possível reduzir a dosagem de cloreto férrico para 5,0 $\mathrm{mg} / \mathrm{L}$ e, ainda assim, atender os parâmetros exigidos para o reuso do efluente, no que tange à turbidez, ao teor de fosfato, ferro e SST. Nessas condições, houve redução de $88,8 \%$ da turbidez, $26,9 \%$ da cor, $88,4 \%$ de SST, $84,4 \%$ de ferro e $77,8 \%$ de fosfato.

\section{CONCLUSÃO}

De acordo com os resultados obtidos com os ensaios em jar test, para reduzir a turbidez do efluente de laminação para valor abaixo de 10 NUT foi necessário usar $20,0 \mathrm{mg} / \mathrm{L}$ de cloreto férrico. Nessa dosagem de cloreto férrico foi observado um aumento de 6,7\% no teor de cloreto em relação à amostra bruta. O uso combinado de 30,0 mg/L de tanino reduziu 75,0\% do cloreto férrico, promovendo a redução de $88,8 \%$ da turbidez, $26,9 \%$ da cor, $88,4 \%$ de sólidos suspensos totais, $94,4 \%$ de ferro e $77,8 \%$ de fosfato. Esses resultados mostram que o tanino é uma alternativa promissora para a redução do uso do cloreto férrico no processo de clarificação de água industrial, pois além de atuar na remoção de partículas finas, o lodo gerado é biodegradável.

\section{REFERÊNCIAS}

ANTOV, M. G.; CIBAN, M. B. S.; PRODANOVIC, J. M. Evaluation of the efficiency of natural coagulant obtained by ultrafiltration of common bean seed extract in water turbidity removal. Ecological Engineering, v. 49, p. 48-52, 2012.

APHA, Standard Methods for the examination of water and wastewater. Washington: American Public Health Association, American Water Works Association, Water Environment Federation., DC, 2012.

GUO B, YU H, GAO B, RONG H, DONG H, MA D, LI R, ZHAO S, Coagulation performance and floc characteristics of aluminum sulfate with cationic polyamidine as coagulant aid for kaolinhumic acid treatment. Colloids and Surfaces A. Physicochem. Eng. Aspects, v. 481, p. 476-484, 2015.

HAMEED YT, IDRIS A, HUSSAIN SA, ABDULLAH N, A tannin-based agent for coagulation and flocculation of municipal wastewater: Chemical composition, performance assessment compared to Polyaluminum chloride, and application in a pilot plant. J. Environ. Manage., v. 184 (3), p. 494-503, 2016.

SÁNCHEZ MJ, BELTRÁN HJ, SOLERA HC, Surface water and wastewater treatment using a new tannin-based coagulant: Pilot plant trials. J. Environ Manage., v. 91, p. 2051-2058, 2010.

THAKUR SS, CHOUBEY S, Use of Tannin based natural coagulants for water treatment: An alternative to inorganic chemicals. Int. J. ChemTech Res, v. 6 (7), p. 3628-3629, 2014. 